\title{
Wernicke's Encephalopathy After Laparoscopic Roux-en-Y Gastric Bypass: A Misdiagnosed Complication
}

\author{
Nishant Tageja
}

Published online: 6 June 2010

(C) Springer Science+Business Media, LLC 2010

I read with interest the paper by Iannelli et al. [1] highlighting the neurological manifestations of thiamine deficiency as a serious complication of bariatric surgery. While the authors have done a good job of describing the case, a few points in the discussion section may need elucidation.

The proclamation that the half-life of thiamine is 10 to 20 days is inaccurate, and this should be corrected. Thiamine deficiency leads to brain lesions-usually constrained to selective, vulnerable regions, with high thiamine content and turnover-within 2-3 weeks [2]. This timescale is related to the time necessary to deplete the body's stores of thiamine which is only sufficient for up to 18 days [3]. The half-life of thiamine after IV administration is $96 \mathrm{~min}$, while the elimination half-life after oral administration is $154 \mathrm{~min}$ [4]. This short half-life necessitates the administration of thiamine three times per day for patients with Wernicke encephalopathy and those at risk of developing it. This thrice daily dosing is mandatory when supplementation is administered orally because the absorption of thiamine in the duodenum is regulated by a rate-limiting process. The calculated maximum amount of thiamine that can be absorbed from a single oral dose in healthy individuals is about $4.5 \mathrm{mg}$, whereas in a patient with chronic malnutrition this amount can be reduced by up to $70 \%$ [5].

Funding source I have not received funding from any source and no disclosures are to be made.

Conflict of interest I have no conflicts of interest.

\section{References}

1. Iannelli A, Addeo P, Novellas S, et al. Wernicke's encephalopathy after laparoscopic Roux-en-Y gastric bypass: a misdiagnosed complication. Obes Surg. 2010 Mar 1. [Epub ahead of print].

2. Schenker S, Henderson GI, Hoyumpa JRAM Jr, et al. Hepatic and Wernicke's encephalopathies: current concepts of pathogenesis. Am J Clin Nutr. 1980;33:2719-26.

3. Sechi GP, Serra A. Wernicke's encephalopathy: new clinical settings and recent advances in diagnosis and management. Lancet Neurol. 2007;6:442-55.

4. Tallaksen CM, Sande A, Bohmer T, et al. Kinetics of thiamin and thiamin phosphate esters in human blood, plasma and urine after $50 \mathrm{mg}$ intravenously or orally. Eur J Clin Pharmacol. 1993;44:73-8.

5. Thomson AD, Cook CCH, Touquet R, et al. The Royal College of Physicians report on alcohol: guidelines for managing Wernicke's encephalopathy in the accident and emergency department. Alcohol 2002;Suppl 37. 513-21.

\footnotetext{
N. Tageja $(\bowtie)$

Department of Internal Medicine, Detroit Medical Center,

Wayne State University,

Detroit, MI 48201, USA

e-mail: ntageja@med.wayne.edu
} 